\title{
Variation of Bulk Etch Rate and some other Etching Parameters with Etching Temperature for Cellulose Nitrate LR-115 Detector
}

\author{
Ali Kh. Hussain \\ Department of Physics / College of Education \\ Mosul University
}

Received

$\cdot 3 / 06 / 200 \wedge$
Accepted

$15 / 10 / 2008$

\begin{abstract}
الملخص
يهدف البحث الحالي إلى دراسـة تغير معدل القتشط العام وبعض المعلمـات القتشطية

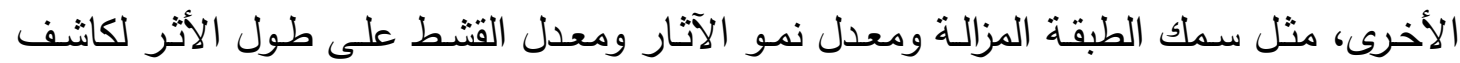

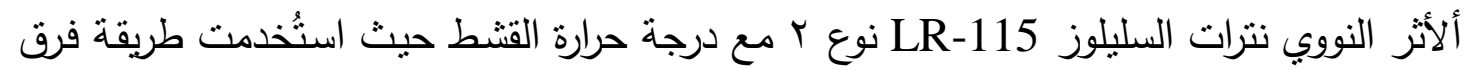
الكتلـة للكاشـف قبـل وبعد قثـطه بمحلـول كيميـائي مـن مـادة

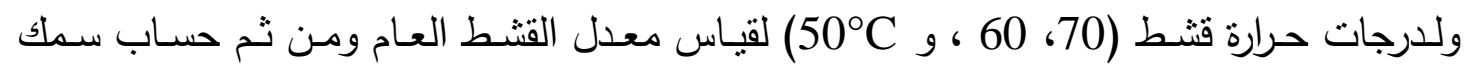
الطبقة المزالـة أثناء فترات القتطط. وقد تم الحصـول على معـادلتين تجريبيتين لحسـاب مقدار h(T,t)] (50-70C C السمك المزال وأقطار الآثار لأي زمن وعند درجات حرارة قثط ما بين

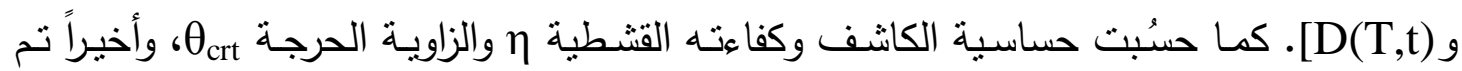
حساب طاقة التنشيط لكل من معدل القتط العام V ومعدل القتط على طول الأثر Vt. وقد أظهرت نتائج الدراسة الحالية تطابق جيد مع تلك المنشورة في الدوريات.
\end{abstract}

\begin{abstract}
In the present work, the variation of the bulk etch rate and some other etching parameters, such as removed active-layer thickness, track growing rate, track etch rate with etching temperature is measured for the solid-state nuclear track detector (SSNTD) LR-115 type 2. The mass difference method is used to measure the bulk etch rate and then the removed active-layer thickness during etching with $2.5 \mathrm{~N}$ aqueous solution of $\mathrm{NaOH}$ as the etchant at etching temperatures 70,60 and $50^{\circ} \mathrm{C}$. Two empirical relationships are derived to calculate the removed activelayer thicknesses and the tracks diameters at any etching time with temperatures as a parameter between $\left(50-70^{\circ} \mathrm{C}\right)$, [i.e. $\mathrm{h}(\mathrm{T}, \mathrm{t})$ and $\left.\mathrm{D}(\mathrm{T}, \mathrm{t})\right]$. The $\mathrm{V}$ function (sensitivity), etching efficiency $\eta$, critical angle $\theta_{\text {crt }}$, and
\end{abstract}


the corresponding activation energies for both the bulk etch rate $\mathrm{V}_{\mathrm{b}}$ and the track etch rate $V_{t}$ are also calculated. The measured and calculated results are in good agreement with those reported in the literature.

\section{Introduction :}

A heavy charged particle leads to an intensive ionization when it passes through a solid-state nuclear track detector. Alpha particles ionize almost all molecules close to its path and create a damaged zone called latent track ${ }^{(1,2)}$. If a piece of material containing latent tracks is exposed to an aggressive chemical solution (such as aqueous $\mathrm{NaOH}, \mathrm{KOH}$ ), the chemical reaction would be more intensive in the latent track. Such a solution is called the etchant. Through the etching, the latent track becomes visible as a particle "track" which may be seen under an optical microscope. This effect called "track effect" ${ }^{(3-5)}$. One of the widely used solid-state nuclear track detector (SSNTD) is the cellulose nitrate (commercially available as LR-115 films) in which visible track can be formed after ion irradiation and suitable chemical etching ${ }^{(6)}$. Ion track growth in SSNTDs has been suggested to base on two parameters ${ }^{(7-14)}, V_{t}$ and $V_{b}$ where $V_{t}$ is the track etch rate (i.e. the track rate of the chemical etching along the ion trajectory) and $\mathrm{V}_{\mathrm{b}}$ is the bulk etch rate (i.e. the rate of chemical etching of the undamaged surface). So the second factor $\mathrm{V}_{\mathrm{b}}$ is strongly related to the removed thickness of the active layer, and many authors had established that the thickness of the removed layer during etching of the solid-state nuclear track detector is one of the main factors influencing the track parameters or shape characteristics ${ }^{(15,16)}$. Other factors, which determine the track parameters and shape, are incident angle, energy and particle charge ${ }^{(17)}$. The mass difference before and after etching is used to determine the bulk etch rate $\left(\mathrm{V}_{\mathrm{b}}\right)$, the removed active layer thickness (h).The measurement of track opening's diameter after the irradiation by alpha particles is also used to determine the track growing rate $\left(V_{d}\right)$. Finally we calculate the track etching rate $\left(V_{t}\right)$, the $(V)$ function which is the ratio between the track etching rate and the bulk etching rate (i.e. $\left.V=V_{t} / V_{b}\right)$, the critical angle $\left(\theta_{\text {crt }}\right)$ and the etching efficiency $(\eta)$.

\section{Experimental method:}

The LR-115 type 2, is used in the present study. The detector consists of a nominal $12 \mu \mathrm{m}$ active layer thick of red cellulose nitrate on a $100 \mu \mathrm{m}$ clear polyester base substrate.

\section{2-1. Bulk Etching Rate:}

To determine the bulk etching rate at different etching temperature, using the mass difference method, the detector should not be irradiated with any charged particle and should be etched for a short time in 
order to keep $\mathrm{V}_{\mathrm{b}}$ constant during etching periods ${ }^{(18)}$. The LR-115 detector were cut with size of about $1.5 \times 1.5 \mathrm{~cm}^{2}$ and etched in $2.5 \mathrm{~N}$ $(10 \%)$ of $\mathrm{NaOH}$ solution at different temperatures 70,60 and $50^{\circ} \mathrm{C}$ in a water bath for different time periods. The temperatures was kept constant with an accuracy of about $\pm 1^{\circ} \mathrm{C}$. For each studied etching temperatures, LR-115 detectors were removed from the etchant at different etching periods and then immediately rinsed by distilled water. After drying, the average mass difference before and after etching were calculated at different time periods.

\section{2-2. Track Diameter :}

The most common method to determine the track etch rates in solid-state nuclear track detectors (SSNTDs) is through measurements of tracks opening's diameters generated from normally incident heavy ions $^{(19)}$.

LR-115 detectors were cut with a size of about $0.7 \times 0.7 \mathrm{~cm}^{2}$. The detectors were irradiated with alpha particles with energy of about 2.5 $\mathrm{MeV}$, because of in the energy range (2-3) MeV the alpha particles can be completely stopped in the detector, have enough range, and formation of the spherical part of tracks is possible ${ }^{(20)}$. The alpha source employ in the present study was a planner ${ }^{241} \mathrm{Am}$ source (main alpha energy $=5.485 \mathrm{MeV}$ under vacuum). Normal air was used as the energy absorber to control the incident energy at the detector surface. The alpha energy controlled using the following relation ${ }^{(21)}$ :

$\mathrm{E}_{\alpha}^{(\mathrm{x})}=\mathrm{E}_{\alpha}^{(0)}(1-\mathrm{X} / \mathrm{R})^{2 / 3}$

Where $\mathrm{E}_{\alpha}^{(\mathrm{x})}$ : Alpha particle energy on the detector surface $(\mathrm{MeV})$.

$\mathrm{E}_{\alpha}^{(0)}$ : Average alpha energy in vacuum.

$\mathrm{X}$ : Distance from the alpha source to the detector surface in $(\mathrm{cm})$.

$\mathrm{R}$ : Average alpha range in air which is equal to $(4.014 \mathrm{~cm})$.

After irradiation, the detectors were also etched in $2.5 \mathrm{~N} \mathrm{NaOH}$ aqueous solution for different time periods in a water bath at different temperatures 70,60 and $50^{\circ} \mathrm{C}$.. At selected time intervals, the detectors were taken out from the enchant, rinsed with distilled water and dried in air. An optical microscope was used to measure the average diameters of the tracks.

\section{Results and Discussion:}

\section{3-1. Bulk Etching Rate:}

After etching the unirradiated detectors, The mass difference before and after etching were measured for different time intervals and different etching temperatures. Figure(1) shows the relationship between the residual mass and the etching times for different temperatures (i.e. 70, 60 
and $50^{\circ} \mathrm{C}$ ). The bulk etch rates at each temperature were calculated using the following relation ${ }^{(22)}$.

$$
\mathrm{V}_{b}=\frac{1}{2} \frac{\Delta \mathrm{m}}{\mathrm{A} \rho \Delta \mathrm{t}}
$$

Where $V_{b}$ : is the bulk etch rate in $(\mu \mathrm{m} / \mathrm{h})$.

$\Delta \mathrm{m}$ : the mass difference before and after etching in $(\mathrm{gm})$.

$A$ : is the etched surface area in $\left(\mathrm{cm}^{2}\right)$.

$\rho:$ is the density of the active layer, which is equal to $\left(1.45 \mathrm{gm} . \mathrm{cm}^{-3}\right)$ for LR-115.

$\mathrm{t}$ : is the etching period in (hr).

Here in our calculation the factor half has been neglected due to one surface etching in LR-115 detectors. The bulk etch rate $\mathrm{V}_{\mathrm{b}}$ was found to be equal to $(7.7708,3.3026$ and $1.3399 \mu \mathrm{m} / \mathrm{h})$ at $\left(70,60\right.$ and $\left.50^{\circ} \mathrm{C}\right)$ respectively.

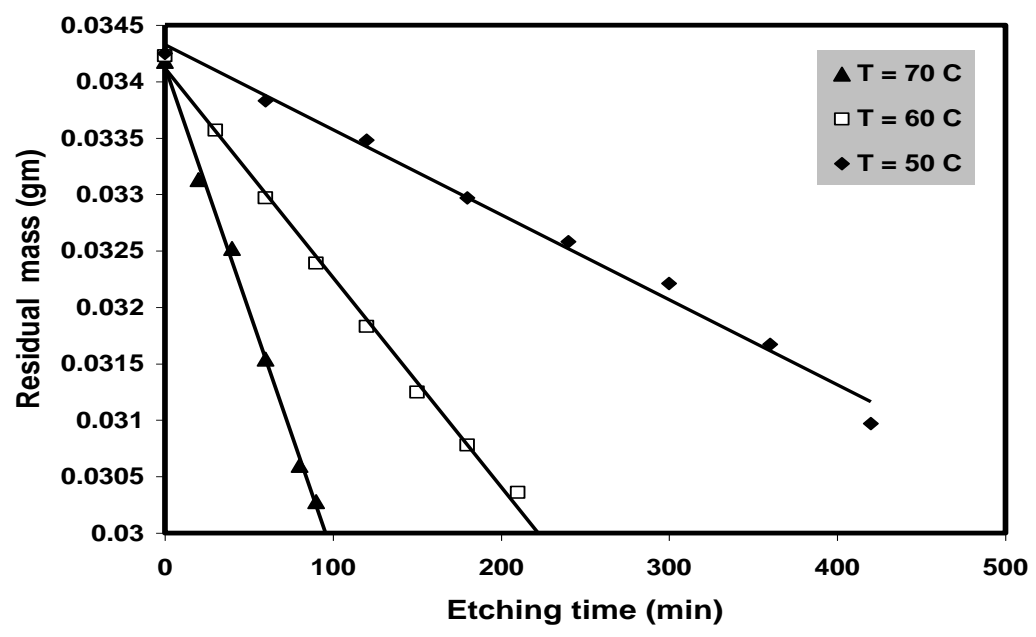

Figure1. The relationship between the residual mass and the etching time at different etching temperatures $\left(70,60\right.$ and $\left.50^{\circ} \mathrm{C}\right)$.

\section{3-2. Removed active layer thickness:}

After calculating the bulk etching rate $\left(\mathrm{V}_{\mathrm{b}}\right)$, it's possible to evaluate the removed-active layer thickness $\mathrm{h}(\mu \mathrm{m})$ at any etching time using the following relation ${ }^{(2)}$ :

$\mathrm{h}=\mathrm{V}_{\mathrm{b}} \cdot \mathrm{t}$

Figure(2) shows the removed active-layer thickness $h(\mu \mathrm{m})$ as a function of etching time $(\mathrm{t})$ for different temperatures $(\mathrm{T})$. By fitting the experimental data in figure(2), we find that the slopes of the lines and the $y$-intercepts are functions of etching temperatures, so an empirical relationship have been derived between the removed active-layer thickness (h), temperature (T) and etching time $(\mathrm{t})$, [i.e. $\mathrm{h}(\mathrm{T}, \mathrm{t})]$, to calculate the removed active-layer thickness at different etching time and temperature. 
$h(T, t)=a_{1} a_{2}{ }^{T} \cdot t+a_{3} \cdot \operatorname{Exp}\left(a_{4} / T\right)$

Where $\left(a_{1}, a_{2}, a_{3}\right.$ and $\left.a_{4}\right)$ are constants, with $a_{1}=0.00029931$, $\mathrm{a}_{2}=1.0905075, \mathrm{a}_{3}=4.1939245, \mathrm{a}_{4}=-272.0997$.

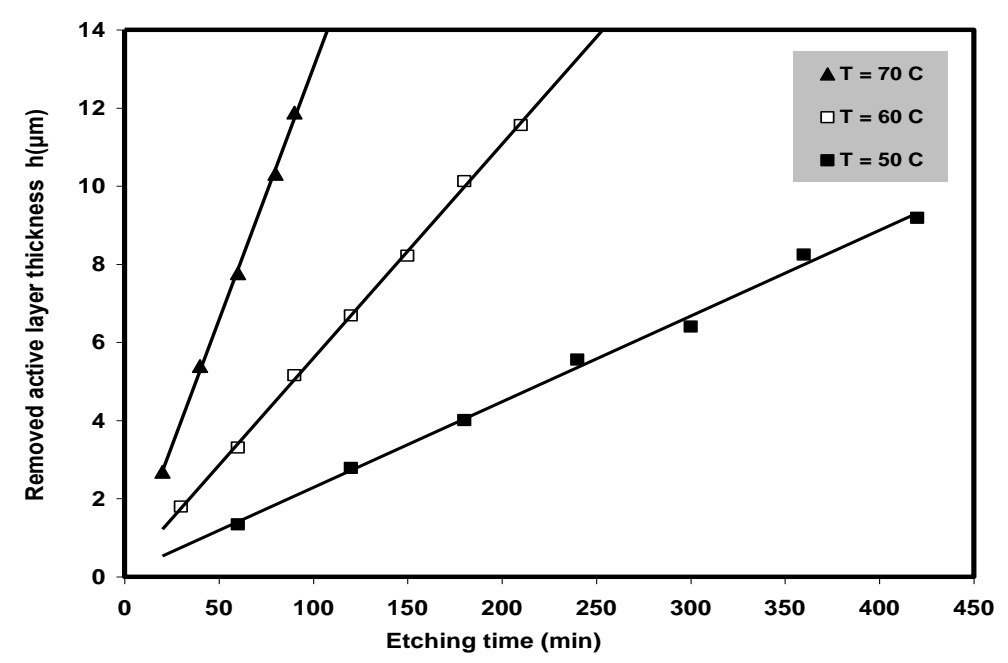

Figure 2. The removed active layer thickness as a function of etching time for different etching temperatures $\left(70,60\right.$, and $\left.50^{\circ} \mathrm{C}\right)$.

\section{3-3. Track Growing Rates Measurement:}

The tracks opening diameters measurements as a function of etching time at different temperatures $\left(70,60\right.$, and $\left.50^{\circ} \mathrm{C}\right)$ are shown in figure (3). Linear relationships are observed. The diameter growing velocity $\mathrm{V}_{\mathrm{d}}$ can be obtained by calculating the slope of diameter-time curve as ${ }^{(23)}$ :

$\mathrm{V}_{\mathrm{d}}=\mathrm{D} / \mathrm{t}$

Where $D$, is the track diameter in $(\mu \mathrm{m}) . t$, is the etching time in (hr).

The track growing rates $\mathrm{V}_{\mathrm{d}}(\mu \mathrm{m})$ was found to be equal to $13.494,5.892$, $2.388 \mu \mathrm{m} / \mathrm{h}$ at the etching temperatures 70,60 , and $50^{\circ} \mathrm{C}$ respectively.

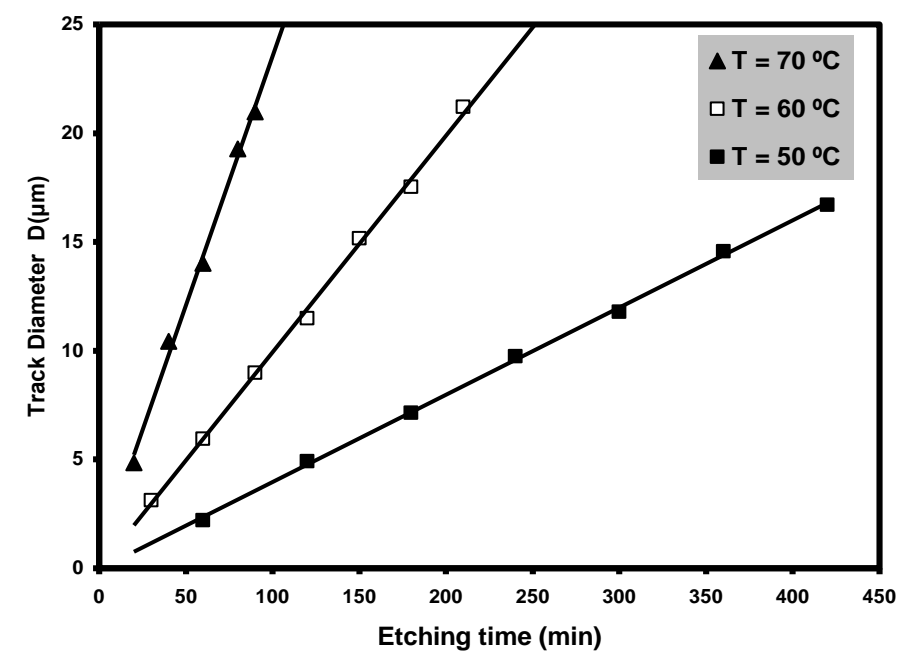

Figure 3. The tracks diameters as a function of etching time for different temperatures $\left(70,60\right.$, and $\left.50^{\circ} \mathrm{C}\right)$. 
In the same way as in section (3-2), an empirical relationship has been derived between track diameter (D) as a function of temperature (T) and time $(t)$, [i.e. $\mathrm{D}(\mathrm{T}, \mathrm{t})$ ], which can be used to calculate the track's diameter at any temperature and time period.

$\mathrm{D}(\mathrm{T}, \mathrm{t})=\mathrm{b}_{1} \mathrm{~b}_{2}^{\mathrm{T}} \cdot \mathrm{t}+\mathrm{b}_{3} \mathrm{~b}_{4}^{\mathrm{T}}$

Where $\left(b_{1}, b_{2}, b_{3}\right.$ and $\left.b_{4}\right)$ are constants, with $b_{1}=0.000606432$, $b_{2}=1.0882076, \quad b_{3}=0.0000118688, \quad b_{4}=1.1707956$. In the present work, the experimental data on the removed active-layer thickness and the tracks opening's diameters $(\mathrm{h}, \mathrm{D})$ have been compared with values calculated using the two empirical relationships $(4,6)$ at the used etching temperatures $\left(70,60\right.$, and $\left.50^{\circ} \mathrm{C}\right)$. We found a good agreement between them as shown in fig.(4).
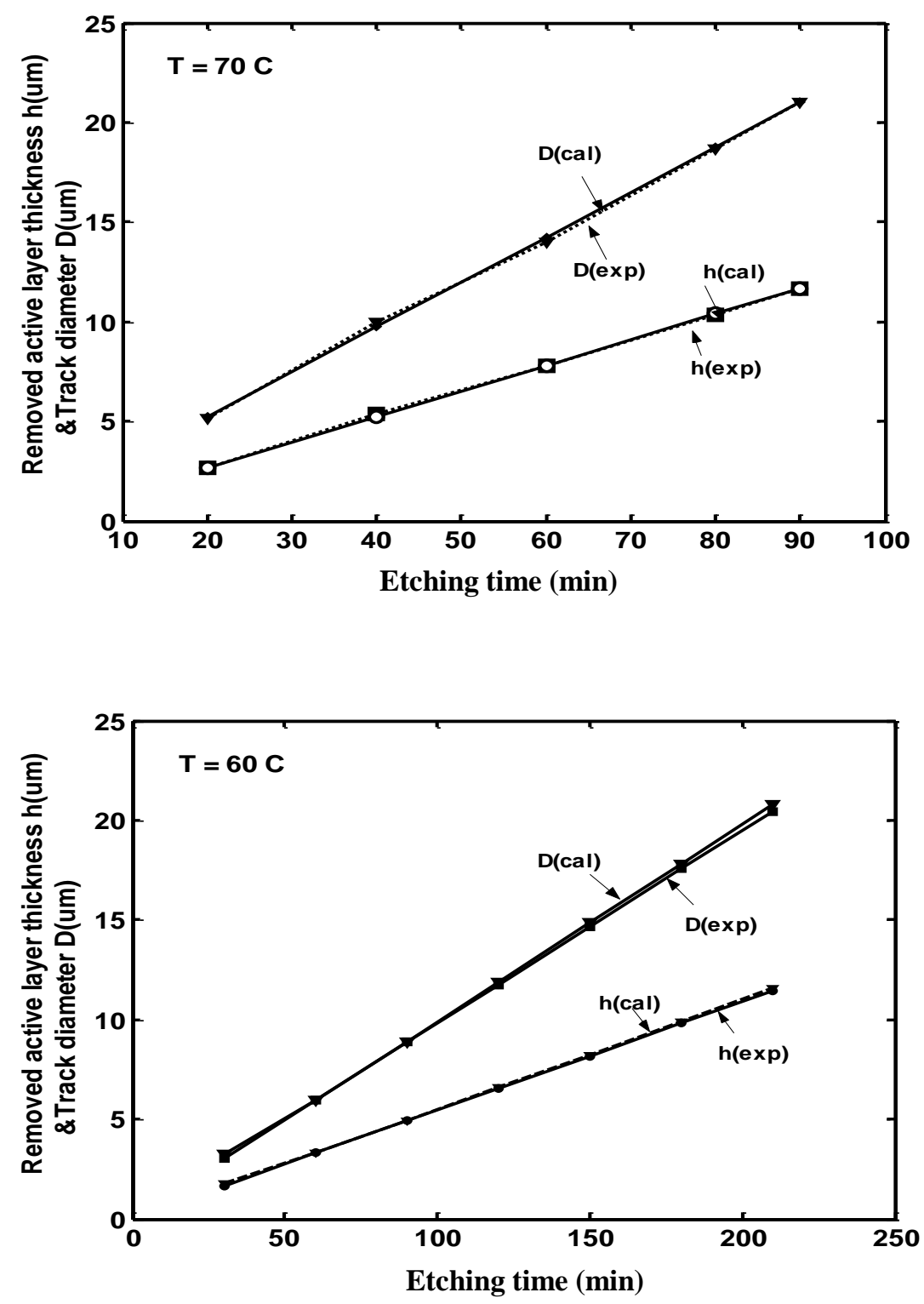


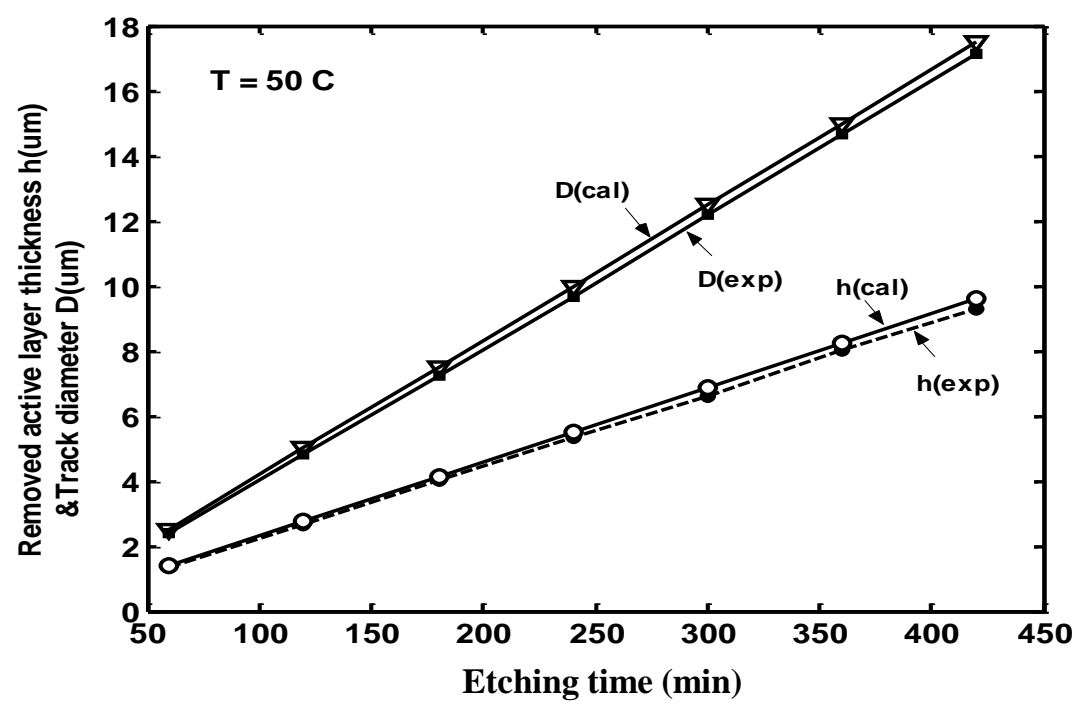

Figure (4). Comparison between calculated and experimental data on the removed layer thickness and the tracks diameters at $\left(70,60\right.$ and $\left.50{ }^{\circ} \mathrm{C}\right)$.

From the Comparison in Figure (4), a good agreement between the calculated $\left(\mathrm{h}_{\mathrm{cal}}, \mathrm{D}_{\mathrm{cal}}\right)$ and experimental $\left(\mathrm{h}_{\mathrm{exp}}, \mathrm{D}_{\mathrm{exp}}\right)$ data on both removed active-layer thickness and tracks diameters can be observed, except a small discrepancy appears at temperature $50^{\circ} \mathrm{C}$, due to long time periods required for etching the LR-115 detectors.

\section{3-4. Examination of the two empirical relationships:}

As well as the comparison mentioned in section (3-3), and in order to test our two empirical relationships, the removed active-layer thickness and tracks diameters are calculated using input etching temperature $\left(65^{\circ} \mathrm{C}\right)$ and time periods from (10-140min) with 10min in step. After that, we measure the removed active-layer thickness and tracks diameters experimentally using the same etching temperature. A good agreement can be seen between them as shown in figure (5).

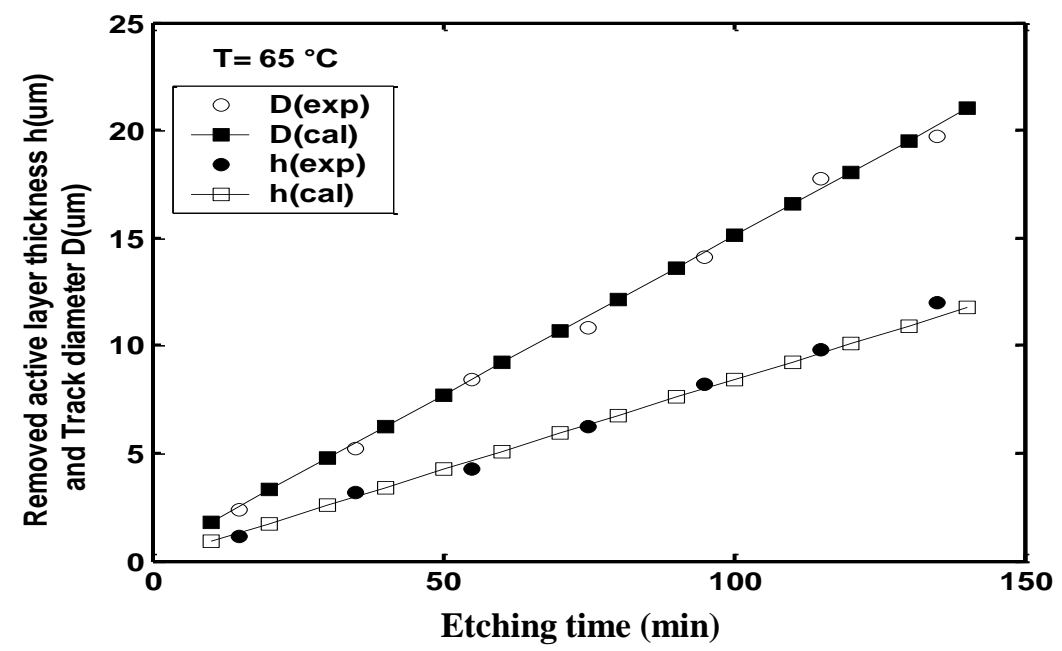

Figure (5). Experimental test to calculated data on the removed active layer thickness and the tracks diameters at etching temperature $\left(65^{\circ} \mathrm{C}\right)$. 


\section{3-5. Track etch rate $V_{t}$ and $V$ function:}

The track etch rate $\mathrm{V}_{\mathrm{t}}$ and the $\mathrm{V}$ function (in some works called sensitivity) can be calculated at each used etching temperatures $\left(70,60\right.$, and $\left.50^{\circ} \mathrm{C}\right)$ using the following relations ${ }^{(22)}$ :

$\mathrm{V}_{\mathrm{t}}=\mathrm{V}_{\mathrm{b}}\left[\left(4 \mathrm{~V}_{\mathrm{b}}^{2}+\mathrm{V}_{\mathrm{d}}^{2}\right) /\left(4 \mathrm{~V}_{\mathrm{b}}^{2}-\mathrm{V}_{\mathrm{d}}^{2}\right)\right]$

$\mathrm{V}=\mathrm{V}_{\mathrm{t}} / \mathrm{V}_{\mathrm{b}}$

The data of some etching parameters are listed in table (1).

\section{3-6. Etching efficiency $(\eta)$ and critical angle $\left(\theta_{\text {crt }}\right)$ :}

In chemical etching there is the simultaneous action of two processes, one along the particle trajectory called the track etch rate $\mathrm{V}_{t}$, and the other as a general attack on the etched surface called the bulk etch rate $\mathrm{V}_{\mathrm{b}}{ }^{(24)}$. The critical angle means that charged particles striking the detector with an angle smaller than $\theta_{\text {crt }}$ cannot produce any track. Etching efficiency and critical angle can be calculated using the following relations ${ }^{(25)}$.

$\eta=1-(1 / \mathrm{V})$

$\theta_{\text {crt }}=\sin ^{-1}(1 / \mathrm{V})$

The values obtained for etching efficiency and critical angle are also listed in table(1).

Table (1) summarizes the etching rates, such as track growing rates $V_{d}$, track etching rates $V_{t}, V$ functions, etching efficiencies $(\eta)$ and critical angles $\left(\theta_{\text {crt }}\right)$ at each used temperatures.

Table(1): Experimental data of some etching parameters for LR-115 detectors.

\begin{tabular}{lccccc}
\hline $\mathrm{T}\left({ }^{\circ} \mathrm{C}\right)$ & $\mathrm{V}_{\mathrm{d}}(\mu \mathrm{m} / \mathrm{h})$ & $\mathrm{V}_{\mathrm{t}}(\mu \mathrm{m} / \mathrm{h})$ & $\mathrm{V}=\mathrm{V}_{\mathrm{L}} / \mathrm{V}_{\mathrm{b}}$ & $\eta$ & $\theta_{\text {crt }}$ \\
\hline 70 & 13.494 & 55.404 & 7.130 & 0.8597 & 8.062 \\
65 & 9.768 & 44.485 & 8.037 & 0.8752 & 7.147 \\
60 & 5.892 & 29.025 & 8.788 & 0.8862 & 6.534 \\
50 & 2.388 & 11.673 & 8.712 & 0.8852 & 6.591 \\
\hline
\end{tabular}

Its obvious that the best etching temperature for the $\mathrm{V}$ function (sensitivity), etching efficiency and the critical angle is about $60^{\circ} \mathrm{C}$, (which is the commonly used etching temperature), as shown in figure (6). The results in table (1) are in a good agreement with the values reported in the literature ${ }^{(17,20,26-29)}$. 

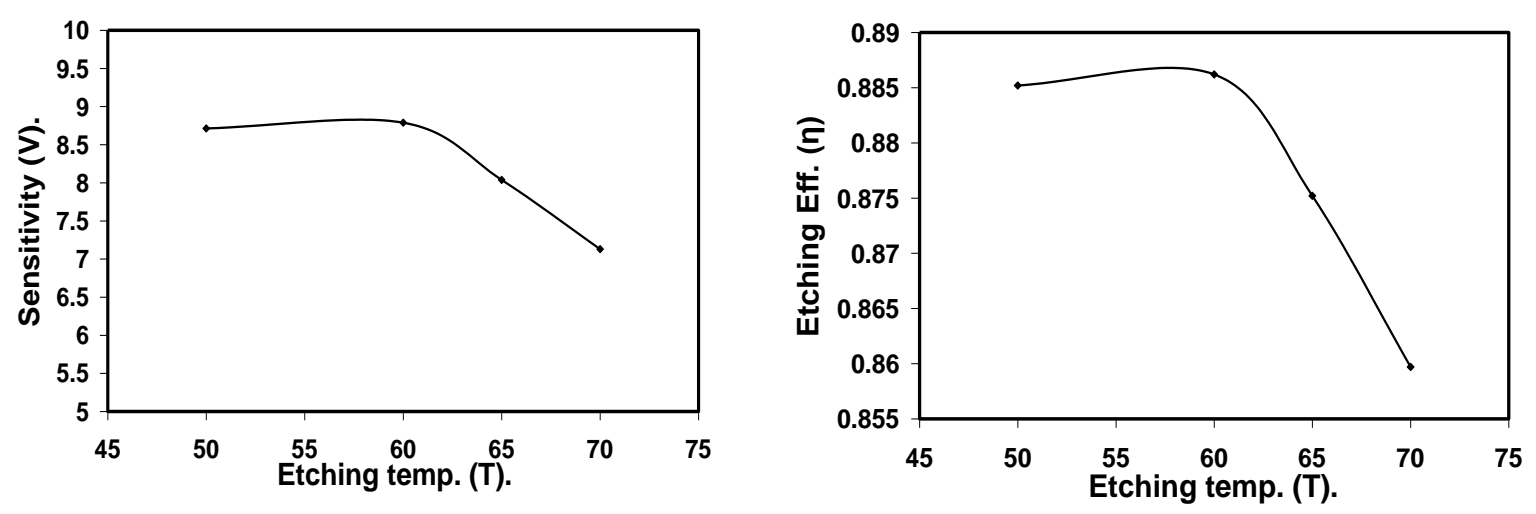

Figure(6). The $\mathrm{V}$ function, Etching eff. $(\eta)$, and critical angle $\left(\theta_{\text {crt }}\right)$ as a function of etching temperature( $T)$.

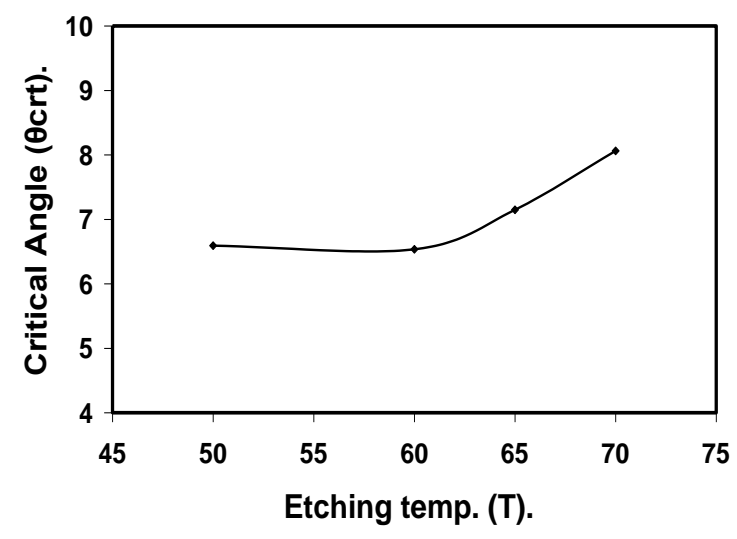

\section{3-6. Activation Energy $\left(E_{a}\right)$ :}

The activation energy is defined as the energy required in activating the reaction between the detector material and the etching solution. And in general the bulk etch rate $\left(\mathrm{V}_{\mathrm{b}}\right)$ of SSNTDs and the track etch rate $\left(V_{t}\right)$ depends on the etching temperature( $\left.T\right)$ through an exponential equations ${ }^{(19)}$.

$\mathrm{V}_{\mathrm{b}}=\mathrm{A} \operatorname{Exp}\left(-\mathrm{E}_{\mathrm{a}} / \mathrm{kT}\right)$

Slope $=\ln \left(V_{\mathrm{b}}\right) /(1 / \mathrm{T})=-\left(\mathrm{E}_{\mathrm{a}} / \mathrm{k}\right)$

$\mathrm{V}_{\mathrm{t}}=\mathrm{A} \operatorname{Exp}\left(-\mathrm{E}_{\mathrm{a}} / \mathrm{kT}\right)$

Slope $=\ln \left(V_{t}\right) /(1 / T)=-\left(E_{a} / k\right)$

Where $A$ is constant, $E_{a}$ is the activation energy, $k$ boltzmann constant, $T$ etching temperature in Kelvin. So, $E_{a}$ can be obtained from the slope of relation(11) between $\ln \left(\mathrm{V}_{\mathrm{b}}\right)$ and $1 / \mathrm{T}$. The data of bulk etching rates and corresponding etching temperatures are shown in figure (7). Linear relationship between $\ln \left(\mathrm{V}_{\mathrm{b}}\right)$ and $1 / \mathrm{T}$ is apparent. By fitting the relationship to the exponential data, we obtained: $\mathrm{E}_{\mathrm{a}}(\mathrm{eV})=8.625 \times 10^{-5} \mid$ Slope $\mid=0.8394$.

Also, $E_{a}$ can be obtained from the slope of relation(12) between $\ln \left(V_{t}\right)$ and $1 / \mathrm{T}$. The data of track etching rates and corresponding etching temperatures are shown in figure (8). Linear relationship between $\ln \left(\mathrm{V}_{\mathrm{t}}\right)$ 
and $1 / \mathrm{T}$ is apparent. By fitting the relationship to the exponential data, we obtain:

$\mathrm{E}_{\mathrm{a}}(\mathrm{eV})=8.625 \times 10^{-5} \mid$ Slope $\mid=0.7306$.

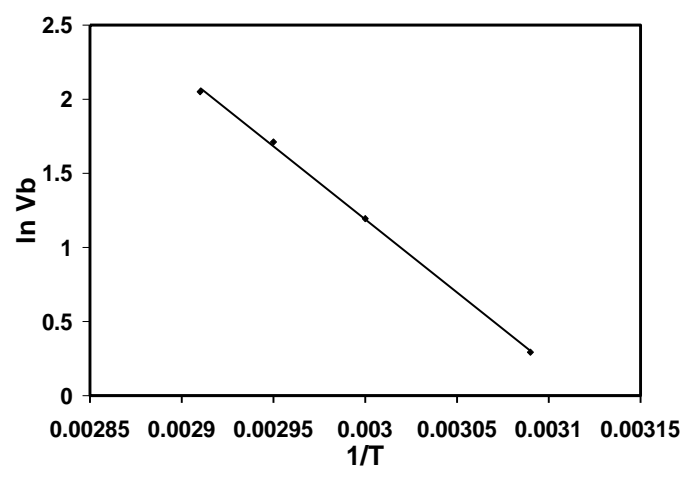

Figure (7). $\ln \left(V_{b}\right)$ as a function of $1 / T$ at used etching temperatures.

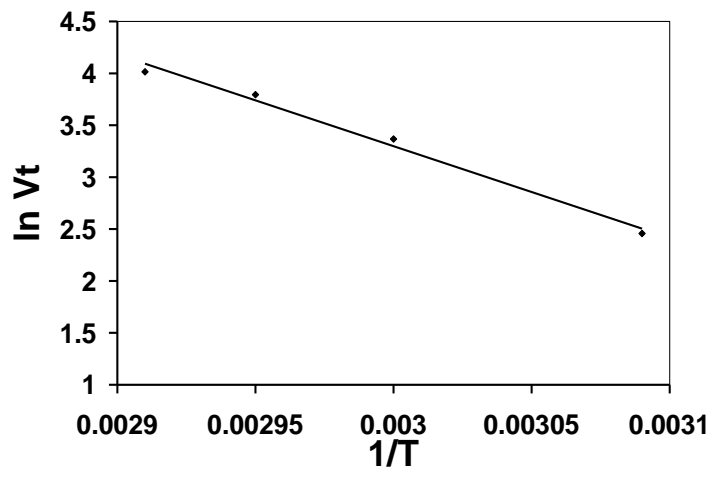

Figure $(8) \cdot \ln \left(V_{t}\right)$ as a function of $1 / T$ at used etching temperatures.

From the calculated data for the activation energy, it's clear that energy required to activate the reaction between the detector material and the etchant along the particle trajectory is less than that required to activate the reaction between the etchant and the undamaged regions (i.e. the etchant solution will penetrate faster in the damaged regions than in undamaged regions). The data are in good agreement with those reported in the literature ${ }^{(19)}$.

\section{Conclusions:}

1. The accuracy of calculations, presented in this study, depend on the accuracy of measurement of mass difference for the LR-115 detector, before and after etching and on the accuracy of tracks opening diameters, as in the most of the nuclear track detectors (SSNTDs).

2. The measured bulk etch rates are $7.7708,3.3026,1.3399 \mu \mathrm{m} / \mathrm{h}$ for etching temperatures 70,60 and $50^{\circ} \mathrm{C}$ respectively. The data show evidence that the bulk etch rate depends on etching temperature through a type equation with the activation energy $0.8394,0.7306 \mathrm{eV}$ for bulk etch rate and track etch rate respectively. These values are in a good agreement with those reported in the literature ${ }^{(19)}$.

3. The calculated etching parameters such as, etching efficiency $(\eta)$, sensitivity (V) and the critical angle $\left(\theta_{\text {crt }}\right.$ ), show that the best etching temperature is about $60^{\circ} \mathrm{C}$ (which is the commonly used etching temperature) as shown in figure(6).

4. Finally, two empirical relationships have been derived to calculate the removed active-layer thickness and tracks diameters as a functions of etching temperature and time duration, [i.e. $\mathrm{h}(\mathrm{T}, \mathrm{t})$ and $\mathrm{D}(\mathrm{T}, \mathrm{t})$ ]. 


\section{Acknowledgment:}

I would like to express my gratitude to Dr. A. K. Mheemeed and Dr. Sa'eed Hassan Sa'eed Al-Nia'emi for their valuable opinions, notices, and their continuous supports.

\section{References:}

(1) D. Nikezic, K. N. Yu, Computer Physics Communications 174 (2006) 160-165.

(2) D. Nikezic, K. N. Yu, material Science and Engineering R46 (2004) 51-123.

(3) D. A. Young, Etching of radiation damage in lithium fluoride, Nature 182 (1958) 375-377.

(4) E. C. H. Silk, R. S. Barnes, Examination of fission fragment tracks with an electron microscope, Phil. Mag. 4 (1959) 970-972.

(5) R. L. Fleischer, P. B. Price, R. M. Walker, Solid state track detectors: Application to nuclear science and geophysics, Ann. Rev. Nucl. Sci. 15 (1965) 1-28.

(6) R. L. Fleischer, J. H. Westbrook, Ion tracks in solid-state detectors, Intermetallic compounds, Principles and practice, Vol. 3, John Wiley, (2002) 263.

(7) P. R. Henke, E. Benton, Nucl. Instr. And Meth. 97 (1971) 483.

(8) G. H. Paretzke, E. Benton, P. R. Henke, Nucl. Instr. And Meth. 108 (1973) 73.

(9) R. L. Fleischer, P. B. Price, R. M. Walker, Nuclear track in solids. Principles and Applications, Univ. of California Press, Berkley, 1975.

(10) G. Somogyi, Nucl. Instr. And Meth. 173 (1980) 21.

(11) M. Fromm, A. Chambaudet, F. Membrey, Nuclear tracks and Radiation Measurements 15 (1988) 115.

(12) U. Hatzialkou, D. L. Henshaw, A. P. Fews. Nucl. Instr. And Meth. A263 (1988) 504.

(13) V. Ditlov, Radiat. Meas. 25 (1995) 89.

(14) P. Meyer, M. Fromm, A. Chambaudet, J. Laugier, L. Makovika, Radiat. Meas. 25 (1995) 449. 
(15) G. Jonsson, Nucl. Instr. And Meth. 10 (1981) 407.

(16) G. Somogyi, A. S. Sazaly, Nucl. Instr. And Meth, 109 (1973) 211.

(17) T. A. Salama, V. Seddik, T. M. Hegazy, A. Ahmed Morsy, Indian Academy of science, 67 (2006) 529-534.

(18) J. P. Y. Ho, C. W. Y. Yip, V. S. Y. Koo, D. Nikezic, K. N. Yu, Radiation Measurements, 35 (2002) 571-573

(19) K. C. C. Tse, F. M. F. Ng, D. Nikezic, K. N. Yu, Nucl. Instr. And Meth, in Physics Research, B 263 (2007) 294-299.

(20) D. Nikezic, K. N. Yu, Nucl. Instr. And Meth, in Physics Research, B 196 (2002) 105-112.

(21) K. Mahesh, S. M. Mustafa, Nuclear Radiation Detectors and Experiments, Mosul University, Press, Iraq (1976).

(22) S. A. Durrani, and R. K. Bull, Solid-state nuclear track detection, Principles, Methods, and Application, Pergamon Press (1987).

(23) Sa'eed Hassan Sa'eed Al-Nia'emi, Ph. D Thesis, Mosul University, Iraq. 1998.

(24) N. E. Ipe, P. L. Ziemer, Submitted to Nuclear Tracks and Radiation Measurements (1985).

(25) H. A. Khan, Nucl. Instr. And Meth. Vol. 125 (1975) 419-423.

(26) J. P. Y. Ho, C. W. Y. Yip, D. Nikezic, and K. N. Yu, Radiation Measurements 36 (2003) 141-143

(27) C. W. Y. Yip, J. P. Y. Ho, D. Nikezic, and K. N. Yu, Radiation Measurements 36 (2003) 245-248.

(28) C. W. Y. Yip, D. Nikezic, J. P. Y. Ho, K. N. Yu, Materials Chemistry and Physics 95 (2006) 307-312.

(29) G. Jonsson, Nucl. Instr. And Meth. 190 (1981) 407-414. 